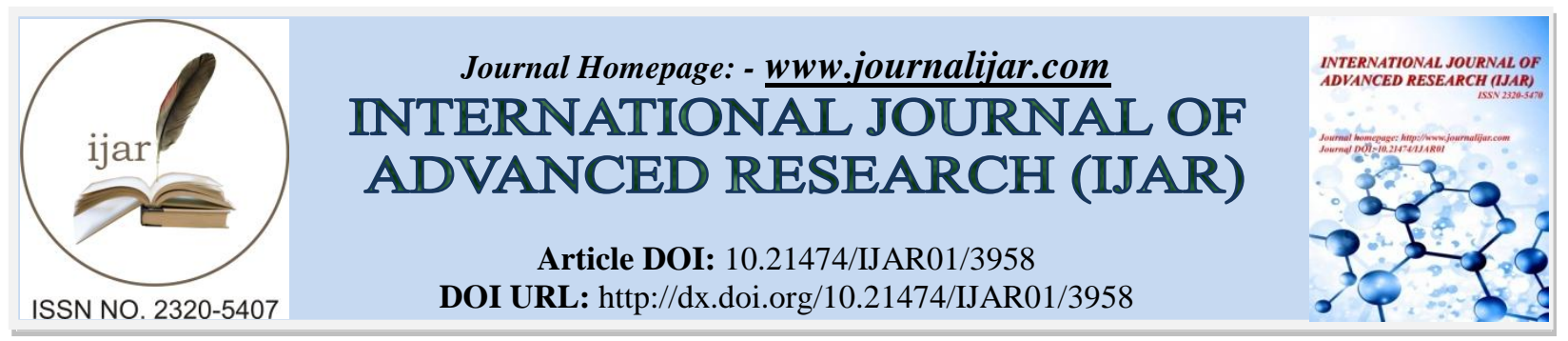

RESEARCH ARTICLE

\title{
STUDY OF CRYSTALLINE PARAMETERS AND DC ELECTRICAL CONDUCTIVITY OF LI-AL FERRITES.
}

Suresh. S. Darokar.

Science College, Congress Nagar, Nagpur-12, Maharashtra, India.

\section{Manuscript Info}

Manuscript History

Received: 12 February 2017

Final Accepted: 16 March 2017

Published: April 2017

Key words:-

M- type Lithium ferrite, DC

Conductivity, Activation energy,

Hopping etc.

\begin{abstract}
$\mathrm{M}$ type lithium ferrites substituted by aluminium having general chemical formula $\mathrm{Li}_{0.5} \mathrm{Fe}_{0.5+\mathrm{x}} \mathrm{Al}_{12-\mathrm{x}} \mathrm{O}_{19}$ (where $\mathrm{x}=1$ to 6) were prepared by standard solid state reaction method The compounds are in single hexagonal phase without traces of uncertainly ambiguous reflection. From XRD pattern lattice parameters has recorded with increasing doped aluminium element in the range from $a=5.807 \AA$ to $5.906 \AA$ and $\mathrm{c}=22.507 \AA$ to $22.585 \AA$ pertaining the space group $\mathrm{P}_{3} / \mathrm{mmc}$ (No.194). The mass density of the ferrites were found linearly varies and depends upon the mass and volume of sample. The X-Ray density has depends upon the lattice constant and molecular weight of the compounds. The average particle size was also estimated. Electrical properties such as dc conductivity, activation energy were studied. Also, the type of carriers responsible in each was determined from thermoelectric studies. The higher resistivity of the compounds $\mathrm{Li}_{0.5} \mathrm{Fe}_{0.5+\mathrm{x}} \mathrm{Al}_{12-\mathrm{x}} \mathrm{O}_{19}$ suggests less presence of mixed valence cations on equivalent lattice. While $\mathrm{Fe}$ show low value due to the ferrous ions present on the octahedral sites along with ferric ions.
\end{abstract}

Copy Right, IJAR, 2017,. All rights reserved.

\section{Introduction:-}

The critical literature survey revealed that the electrical properties of hexagonal [1-4] M-type ferrites are less studied compared to its magnetic properties. This may be due to the fact that they were developed initially as permanent magnet.[5-8] Today M-type ferrites are finding applications in many diverse fields like microwave and hence their electrical properties are also becoming important. Many attempts have been made to improve the properties of $\mathrm{M}$ ferrites by variety of substitutions. Though M-type ferrite does not contain any monovalent cation, hence a combination of monovalent cation with some multivalent cations for charge compensation may be substituted. With this idea, a new series of materials for permanent magnets of Ba-ferrites were developed for the first time.[9-10]. Since the properties of ferrite depend on the interactions among the cations distributed over various sites, these were explained on the basis of the knowledge of site distribution of cations in the magnetoplumbite structure. In the present work M-type ferrites having common formula $\mathrm{Li}_{0.5} \mathrm{Fe}_{0.5+\mathrm{x}} \mathrm{Al}_{12-\mathrm{x}} \mathrm{O}_{19}$ were prepared and their electrical properties such as conductivity, activation energy and thermoelectric power were studied

\section{Materials and Methods:-}

The M-type compounds in the present investigations were prepared using the standard solid-state reaction method.[11,12] using AR grade oxides as starting materials. Preparation of ferrites from Hexagonal family are usually difficult as compared to Spinel ferrites and especially the M-type ferrite is one of the most difficult one. This 
is due to the higher formation temperature and difficulty to get a pure product. The prolonged and continuous heating $\left(1200^{\circ} \mathrm{C}\right.$ sintering temperature maintained for about 120 hours) used in present work resulted in better product formation as this has given sufficient time to the ions to diffuse. Also the lithium present, in these compounds might have facilitated the synthesis.

In the present work X-ray diffractometer with filtered $\mathrm{Cu} \mathrm{K}_{\alpha}$ radiation from X-ray tube, operating at $40 \mathrm{KV}$ and 20 $\mathrm{mA}$ were used for identification of compounds. (Philipse PW 1710). From the X-ray graph, formation of hexagonal structure, corresponding to space group $\mathrm{P}_{6}^{3} / m m c$ or $\mathrm{D}_{6}^{4} \mathrm{~h}$ (No 194) was checked.

Two-terminal method was employed for measurement of dc electrical conductivity. The measurements were taken in the range from $150{ }^{\circ} \mathrm{C}$ to $700{ }^{\circ} \mathrm{C}$. Finally graphs of $\ln \sigma$ against $1 / \mathrm{T}$ were plotted and from the slope of these graphs the activation energies for the compounds were calculated using the relation,

$\Delta \mathrm{E}=8.617 \times 10^{-5}[\Delta(\ln (1 / \sigma) / \Delta(1 / \mathrm{T})]$

The Seeback coefficient measurements were carried out using two-probe set up fabricated in the laboratory. The measurements were taken in the temperature range $350^{\circ} \mathrm{K}$ to $450^{\circ} \mathrm{K}$. The type of carriers responsible for conduction was determined in each of the compound from these studies. In order to prepare pellet for the above observations the compound prepared was grounded to fine particle size in an agate mortar. The powder was mixed with 5\% polyvinyl acetate solution made in A.R. grade acetone, as binder and mixed thoroughly. This mass was then transferred to a die and pressed under pressure of 5 tons per $\mathrm{cm}^{2}$ using a hydraulic press. The pellets so prepared were then heated in a furnace up to $500{ }^{\circ} \mathrm{C}$ to remove the binder. After maintaining this temperature for few hours the pellets were slowly cooled to room temperature. In this way crack free pellets in the shape of a cylinder of small height were obtained. The end faces of the pellets, so prepared, were gently grounded over zero number sand paper to ensure smooth surfaces. The dimensions of the pellets were measured accurately. The smooth and flat parallel faces of the pellets were coated with uniform thin layer of silver paste to facilitate a good electrical contact with the electrodes. The silver paste was dried by heating the pellet slowly for few hours in air at $500{ }^{\circ} \mathrm{C}$. The thin coating of silver paste thus formed was adherent and chemically inert. Pellets were stored in desiccators if found necessary.

\section{Results and discussion:-}

The consolidated data of lattice parameters, Molecular weights and X-ray densities derived from the X-ray diffraction study, for the compounds studied in the present work, are given in table No.1. The formation of predominant $\mathrm{M}$ phase in all the compounds was confirmed from the X-ray study (figure No. 1).

Table-1:- Crystallographic data of lithium hexaferrites [ $\mathrm{Li}_{0.5} \mathrm{Fe}_{0.5+\mathrm{x}} \mathrm{Al}_{12-\mathrm{x}} \mathrm{O}_{19} \quad$ where $\left.(\mathrm{x}=2,3,4,5 \& 6)\right]$

\begin{tabular}{|c|c|c|c|c|}
\hline Compounds & $a$ (A.U.) & c (A.U.) & $\begin{array}{c}\text { Mol. Wt } \\
\text { in gm }\end{array}$ & $\begin{array}{c}\text { X-ray density } \\
\text { gm/cm }\end{array}$ \\
\hline $\mathrm{Li}_{0.5} \mathrm{Fe}_{2.5} \mathrm{Al}_{10} \mathrm{O}_{19}$ & 5.8594 & 22.3234 & 780.89 & 3.9065 \\
\hline $\mathrm{Li}_{0.5} \mathrm{Fe}_{3.5} \mathrm{Al}_{9} \mathrm{O}_{19}$ & 5.8181 & 21.8796 & 841.79 & 4.3578 \\
\hline $\mathrm{Li}_{0.5} \mathrm{Fe}_{4.5} \mathrm{Al}_{8} \mathrm{O}_{19}$ & 5.8076 & 21.8411 & 902.66 & 4.6992 \\
\hline $\mathrm{Li}_{0.5} \mathrm{Fe}_{5.5} \mathrm{Al}_{7} \mathrm{O}_{19}$ & 5.7948 & 21.8077 & 963.54 & 5.0473 \\
\hline $\mathrm{Li}_{0.5} \mathrm{Fe}_{6.5} \mathrm{Al}_{6} \mathrm{O}_{19}$ & 5.6953 & 21.2626 & 1024.4 & 5.6963 \\
\hline
\end{tabular}

$\mathrm{X}$-ray diffraction pattern of $\mathrm{Li}_{0.5} \mathrm{Fe}_{0.5+\mathrm{x}} \mathrm{Al}_{12-\mathrm{X}} \mathrm{O}_{19}$

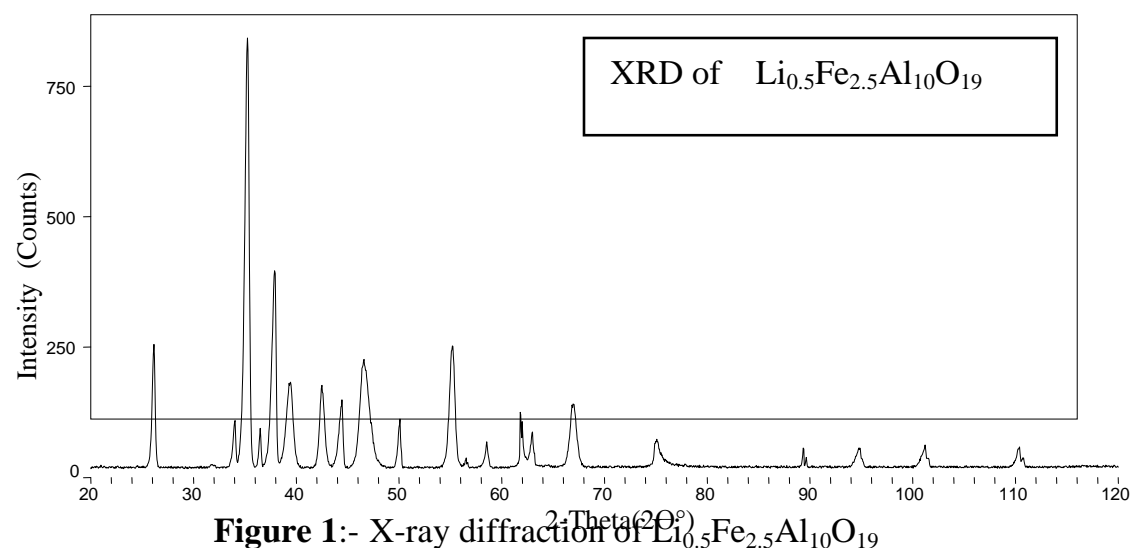


All the compounds were prepared in polycrystalline form using stoichiometric mixtures of oxides with standard ceramic technique. The phase unicity of the samples were verified by using X-ray diffraction technique. The hexagonal lattice parameters of the compounds were deduced from XRD-pattem. The structural data viz. $d$ observed and $\mathrm{d}_{\text {calculated }}$ values and intensity observed with reflection hkl indices and the patterns are shown in figure-1. The crystallographic analysis of the samples shows single phase with magnetoplumbite structure. The variation of lattice parameters and cell volume decreases linearly with increase in $\mathrm{Al}^{+3}$ and $\mathrm{Fe}^{+3}$ concentrations. The decrease in lattice parameters and cell volume agree well with the results of Haneda and Kojima[11] for the Ba-ferrites. In M-ferrites, in which the $\mathrm{Fe}^{+3}$ ions occupy five crystallographic sites viz 2a, 2b. 4fi, 4fa and 12k Lipka et.al. (1990)[12]. The magnetic behavior of the compounds has been explained, mainly due to the interactions amongst the ions occupying these five sites. Due to several possible site distributions, various comparative magnetic interactions can arise in the lattice and in turn all these decides magnetic properties.

The results of dc electrical conductivity study are shown in the form of plots of conductivity lno against inverse absolute temperature. Variation of activation energy, electrical resistivity and electrical conductivity with Al ions in lithium ferrite is shown in figure No. 2. and compiled in the table No 2. It was observed that the conductivity increases with temperature in all compounds and follows Wilson's law $\sigma=\sigma_{\mathrm{o}} \exp (\Delta \mathrm{E} / k \mathrm{~T})$. This indicates semiconducting nature of the compounds. The large values of resistivity and activation energy are attributed to the relatively low number of mixed valence state of an element on an equivalent lattice sites. The increase in conductivity with temperature is attributed to the greater overlap of orbital due to the increased lattice vibrations. Since the overall distances get reduced during overlap, there is a greater probability of exchange of charges between the two overlapping ions. This increased exchange might have led to increase the conduction in the compound. .[13]

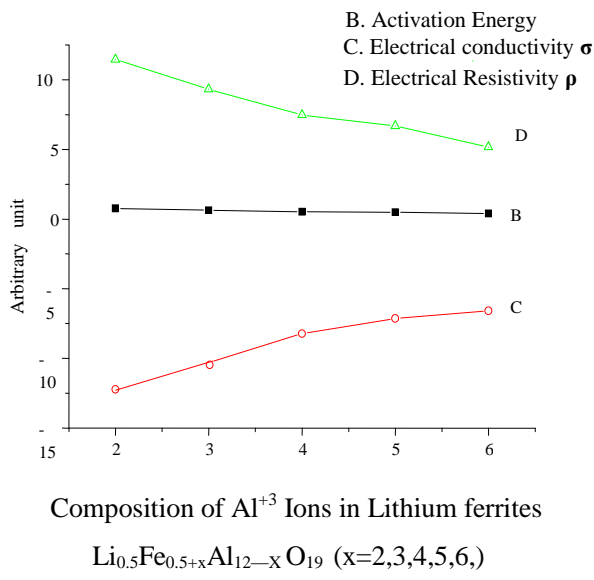

Fig . 2

The various divalent cations may be categorized as per their atomic radii, masses, magnetic nature and most importantly their site preferences. The exchange interactions responsible for conduction mechanism depends on the overlapping of orbits and hence on actual locations of cations. Therefore the site distribution of these cations on various sites influences the conduction process and hence decides the conductivity of a M-type ferrite. As a result the conduction properties of the compounds prepared in the present work could be explained on the basis of distribution of cations.

The electrical properties of the $\mathrm{Li}_{0.5} \mathrm{Fe}_{0.5+\mathrm{x}} \mathrm{Al}_{12-\mathrm{X}} \mathrm{O}_{19} \mathrm{M}$ - type ferrite has been explained on the basis of the hopping of electrons in between the ferrous and ferric cations $\left(\mathrm{Fe}^{2+} \rightarrow \mathrm{Fe}^{3+}\right)$ present on the octahedral sites. The small quantity of $\mathrm{Li}$, though occupies some of the octahedral sites, there is enough space on these sites for the iron cations. It has been revealed from the Mossbauer and other studies that the divalent $\mathrm{Fe}^{2+}$ cations locate on the octahedral sites of S-block.[14-15] Due to this, iron cations of mixed valency on the octahedral sites are developed, which facilitated the electrical conduction. The lowest value of room temperature resistivity for this compound, among all the compounds studied in present work, could be attributed to this phenomenon. It can be that the conductivity value obtained for the compounds in the present investigation is $2.193 \times 10 \mathrm{ohm}^{-1} \mathrm{~cm}^{-1} 5.78 \times 10^{16} \mathrm{ohm}^{-1} \mathrm{~cm}^{-1}$. There values of the conductivity may be partly attributed to the low evaporation of lithium from the samples prepared. 
Table-2:- Electrical Conductivity and activation energy of Li- $\mathrm{Al}$ ferrites

\begin{tabular}{|c|c|c|c|}
\hline Compounds & $\begin{array}{c}\text { Resistivity } \rho \\
\text { at room Temp. } \\
(\text { ohms cm) }\end{array}$ & $\begin{array}{c}\text { Activation } \\
\text { Energy } \\
\Delta \mathrm{E}(\mathrm{ev})\end{array}$ & $\begin{array}{c}\text { Conductivity } \sigma \\
\text { at room temp } \\
\left(\mathrm{ohms}^{-1} \mathrm{~cm}^{-1}\right)\end{array}$ \\
\hline $\mathrm{Li}_{0.5} \mathrm{Fe}_{2.5} \mathrm{Al}_{10} \mathrm{O}_{19}$ & $4.08 \times 10^{11}$ & 0.73 & $2.447 \times 10^{-11}$ \\
\hline $\mathrm{Li}_{0.5} \mathrm{Fe}_{3.5} \mathrm{Al}_{9} \mathrm{O}_{19}$ & $8.21 \times 10^{8}$ & 0.60 & $1.218 \times 10^{-11}$ \\
\hline $\mathrm{Li}_{0.5} \mathrm{Fe}_{4.5} \mathrm{Al}_{8} \mathrm{O}_{19}$ & $6.21 \times 10^{8}$ & 0.57 & $1.631 \times 10^{-9}$ \\
\hline $\mathrm{Li}_{0.5} \mathrm{Fe}_{5.5} \mathrm{Al}_{7} \mathrm{O}_{19}$ & $2.38 \times 10^{7}$ & 0.50 & $4.196 \times 10^{-8}$ \\
\hline $\mathrm{Li}_{0.5} \mathrm{Fe}_{6.5} \mathrm{Al}_{6} \mathrm{O}_{19}$ & $2.147 \times 10^{6}$ & 0.45 & $4.656 \times 10^{-7}$ \\
\hline
\end{tabular}

\section{Conclusion:-}

The formations of compounds were tested by XRD technique. The replacement of $\mathrm{Fe}^{+3}$ ions by $\mathrm{Al}^{+3}$ ions has been investigated because of resemblance of the ionic radii. It is seen that the former ions are very easily replace at any substitution ratio without changing the crystal geometry. The lattice parameter ' $a$ ' and ' $c$ ' decrease linearly with substitution ratio in all compounds. The numerical value of the compositional data such as lattice constant, cell volume and $\mathrm{X}$ - ray density are reported and same nature in $\mathrm{Ba}$ and $\mathrm{Sr} \mathrm{M}$ - ferrite.

The dc electrical conductivity of all the compounds has been calculated from the resistivity measurements, from room temperature to $850^{\circ} \mathrm{K}$. The consolidated results of resistivity and electrical conductivity at room temperature and activation energies $\Delta \mathrm{E}(\mathrm{ev})$ of all the compounds are determined. The resistivity of the compounds show low value due to the ferrous ions present on the octahedral sites along with ferric ions and as a result the conduction takes place in the form of hopping of electron from ferrous to ferric ion. The variation of resistivity in these compounds can be explained on the basis of Verway mechanism[16]. Where the conduction is due to the electron exchange between ions $\mathrm{Fe}^{+3}$ and $\mathrm{Fe}^{+2}$ of the same element present in more than one valence state. The unreacted impurities probably contain same $\mathrm{Fe}^{+2}$ ions which have migrated in growing particles of ferrite $\left(\mathrm{Fe}^{+3}\right.$ species) subjected to proper sintering of samples. The concentrations of $\mathrm{Fe}^{+2}$ ions so produced are negligibly small which were not detected.

\section{References:-}

1. J. Beretea and T.Brown.Austral.,J.Chem.24(1971) 273

2. G.Albanese, A Deriu, E.Luchini and G.Slokar.,Appli Phys A 2(1981) 45

3. B.X.Gu, H.Y.Zang. H.R.Zhai, B.G.Slen, M.Lu, S.Y.Zhang and Y.Z.Maoi., J Phys State Sol 133 (1992) K83

4. Hanmawalt (1936) International table for X-ray diffraction photograph

5. X.Obrador, A Isalgue,A Collomb, A Tejeda, J.C.Joubert., J.,PhysC. 19(1986) 6605

6. D.B.Ghare, A.P.B.Sinha., J.Phys Chem Solid 29(1958) 885

7. Isalgue, A Laberta, J.Tejada, X Obradir., Appl.Phys A39(1986) 221

8. S.S.Darokar, K.G.Rewatkar and D.K.Kulkarni., Mater Chem.Phys.56 (1998) 84-85

9. K. Haneda, M. Kojima., J. Appl. Phys 14.B(1973) 3760

10. Albense G, Carbulichhio and Deril A., J.Phys Solid State: A 23 (1974) 351

11. K.Haneda, H.Kojima., Phys State Solid (A) 6(1971) 256

12. J.Lipka,A. Gruskova, O.Orlicky, J.Siteck, M.Miglierini, R.Grone, M.Hud and Toth., Hyperfine Interaction 59(1990) 381.

13. S.S.Darokar,K.G.Rewatkar and D.K.Kulkarni.,Indian J.Phys74A (2) (2000) 155-157

14. Suresh. S. Darokar et.al., J. Adv. Appl. Sci. Res, 2013, 4(1): 173-177

15. Z.Redrigue,Obradors X,Labrata A,Tejeja.J.Pernet M.M.Solid Paul and J.Tholente.,J.Phys Collog,149(1988) 119

16. E.J. Verway J.H, De-Bar.,Pec.Trar.Chem Pay Bull 55 (1936)531 